\title{
Experimental Efficiency Investigation on Heat Recovery System Used in a Solar-Powered Desalination Process
}

\author{
${ }^{1}$ Aouatef Rachdi, ${ }^{2}$ Louy Qoaider, ${ }^{3}$ Mahmoud Ben-Amara and ${ }^{3}$ AmenAllah Guizani \\ ${ }^{1}$ Higher Institute of Industrial Systems of Gabes, \\ Slaheddine El Ayoubi Street- 6032 Gabes, Tunisia \\ ${ }^{2}$ German Aerospace Center (DLR) Plataforma Solar de Almería, \\ Paseo de Almería, 73, 04001 Almería, Spain \\ ${ }^{3}$ Laboratory of Thermal Process, Research and Technologies Center of Energy, \\ Ecoparck of BorjCedria, BP 95 Hammam lif 2050, Tunisia
}

\begin{abstract}
The aim of this work is to experimentally study, the effect of the heat recovery on water production in a solar desalination process that is working with multiple stage humidification technique. The water production, the temperature and the humidity were tested for such a pilot plant, which operates without and with a heat recovery system. The humidifier efficiency increases with the number of the operating heat exchangers and cannot normally exceed $45 \%$ when the system operates without heat exchangers. The air temperature in the heat exchangers decreases by $41.1,39.2$ and $36^{\circ} \mathrm{C}$ respectively when the system operates with three heat exchangers, tow heat exchangers in the and only one heat exchanger. The number of the heat exchanger use for heat recovery system in such desalination pilot plant has a significant influence on the water productivity. In short, results show that such a pilot plant working without the use of a heat recovery system (heat exchangers) is unable to deliver the desirable minimal amount distilled water at the exit of the condenser. Furthermore, the optimum number of heat exchangers that should be used to upgrade the overall efficiency of the desalination plant is two.
\end{abstract}

Keywords: Solar Desalination, Humidification Technique, Heat Recovery System, Distilled Water

\section{INTRODUCTION}

Major desalination processes require large amount of energy derived commonly from fossil fuels in form of heat and electricity, while emitting harmful $\mathrm{CO}_{2}$. In contrary, solar desalination has emerged as a promising renewable energy powered technology for proucing fresh water. Furthermore, the humidificationdehumidification desalination process is an attractive desalination process because of its simple layout and that it can be combined with solar energy. The combination of the humidification-dehumidification principle with solar desalination should result in an increase in the overall efficiency of desalination process that would make the solar desalination an even more promising method (Al-Hallaj et al., 2006). On the other hand, the large surface of the solar collectors (source of energy) and heat losses are the most significant deficiencies of such desalination process.

Goosen et al. (2000) reviewed various layouts of the humidification-dehumidification desalination systems as well as single and multiple effect solar desalination. The authors stressed the fact that many of these units are limited to theoretical evaluation or prototype scale. However, the steady increase in future demand for fresh water might make these processes viable for fresh water production. MullerHolst et al. (1999) described the performance of an optimized humidification-dehumidification desalination system, which is associated with a solar Corresponding Author: Aouatef Rachdi, Higher Institute of Industrial Systems of Gabes, Slaheddine El Ayoubi Street-6032 Gabes,
Tunisia 
collector. A main feature of this patented configuration is that the flow of the air stream is driven by natural convection. Importantly, the continuous operation of this unit requires the use of heat storage. The minimal maintenance requirements make this system adequate for operation in remote areas. This is resulted partially by low temperature operation of the system that minimizes the rate of scale formation. Farid and Al-Hallaj (1999) constructed a small-scale humidification-dehumidification unit with a productivity of $21 / \mathrm{m}^{2}$.day. This system comprises a combination of a water heater and a solar collector. Other studies by (Al-Hallaj et al., 1998; Nawayseh et al., 1997; 1999a; 1999b) covered additional aspects, which include modelling, evaluation of the heat and mass transfer coefficients and field performance. Al-Enezi et al. (2006) measured the performance of a humidification-dehumidification system at low temperatures and reported that a low conversion ratio of less than $0.01 \mathrm{~kg}^{-1}$ product per one $\mathrm{kg}$ water that flows into the humidifier. Accordingly, the overall heat transfer coefficient in the condenser and the overall mass transfer coefficient in the humidifier were measure. Ettouney (2005) analyzed several layouts for the humidification-dehumidification process that include the conventional system combined with either one of the following units to condense/extract the water vapour from the air: (1) water condenser, (2) membrane air drying, (3) vapour compressor, (4) lithium bromide absorption desorption.

The analysis of the above listed literature results shows that there is a need and potential for further evaluation and optimization of the described process. This aims at determining a more efficient design and operating conditions to produce fresh water at the lowest possible cost.

Based on the above investigated published works, it can be summarized that most of the preceding studies have used solar thermal energy for water heating before the humidification process. In this work, we used solar collectors for air heating before its humidification; while salt water was heated by means of exchangers used in a heat recovery system (see detail in (Chafik, $2002 ; 2003)$. The main idea of the present process is a stepwise loading of air with water vapour. The process consists of several steps of air heating, each followed by a humidification stage. This of operation makes it possible to obtain a high vapour concentration in the airflow, thus reducing the airflow rate through the plant (Chafik, 1999).

Based on this idea, a desalination pilot plant using stepwise heating-humidifying procedure was designed and constructed. Preliminary experiments (Ben-Amara et al., 2004a) were conducted to optimize the experimental setup and lead to select the following operating parameters as optimum: water to air mass-flow ratio $\mathrm{R}=45 \%$, air mass flow rate $\mathrm{M}_{\text {air }}=790 \mathrm{~kg} \mathrm{~h}^{-1}$, the number of heatinghumidifying stages: 5 . These results are specific for the Tunisian climatic conditions of $590 \mathrm{~W} / \mathrm{m}^{2}$, as annual average solar radiation intensity (Ben-Jemaa et al., 1999). The performance of the solar collectors and the humidifier while the pilot plant operates and produces distilled water, have been studied (Ben-Amara et al., $2005 ; 2004 b ; 2004 c)$. Other measured data related to the operating parameters of each single component of the process such as collectors' outlet temperatures, humidifier parameters as well as the daily and monthly fresh water production of the pilot plant have been presented by Houcine et al. (2006).

Common findings among various studies indicate that most of the previous efforts have targeted the study of the solar collectors, the humidifier and the overall pilot plant performance without stressing on the heat recovery system. The aim of the present work is to investigate the importance of the heat recovery in such thermal desalination process. In this regard, experimental results of the pilot plant working without and with heat recovery system to produce water will be presented in this work in order to optimize the heat exchanger surface.

\section{MATERIALS AND METHODS}

\subsection{Solar Desalination Pilot Plant}

The pilot plant configuration shown in Fig. 1 consists mainly of an air fan, air plate solar collectors, humidifiers, heat exchangers for heat recovery and a condenser beside auxiliary components such as water tanks and pumps. The fan blows air into the first stage of air plate solar collectors (9 collectors in parallel, total area is $45 \mathrm{~m}^{2}$ ) to be heated and then loaded with water vapour in the first pad humidifier. Thereafter, the humid airflow enters into the second stage of air plate solar collectors ( 9 collectors on parallel, total area is $45 \mathrm{~m}^{2}$ ) and then to the second pad humidifier. Next the airflow continues to enter successively into a super heated stage of air collectors before it flows through the heat recovery system, which is constituted by three heat exchangers and finally enters to the condenser, which is connected to the inlet of the air fan to close the loop. Likewise, the seawater is pumped up from the storage tank to enter successively into the three heat exchangers (E1, E2 and E3) to be heated. 

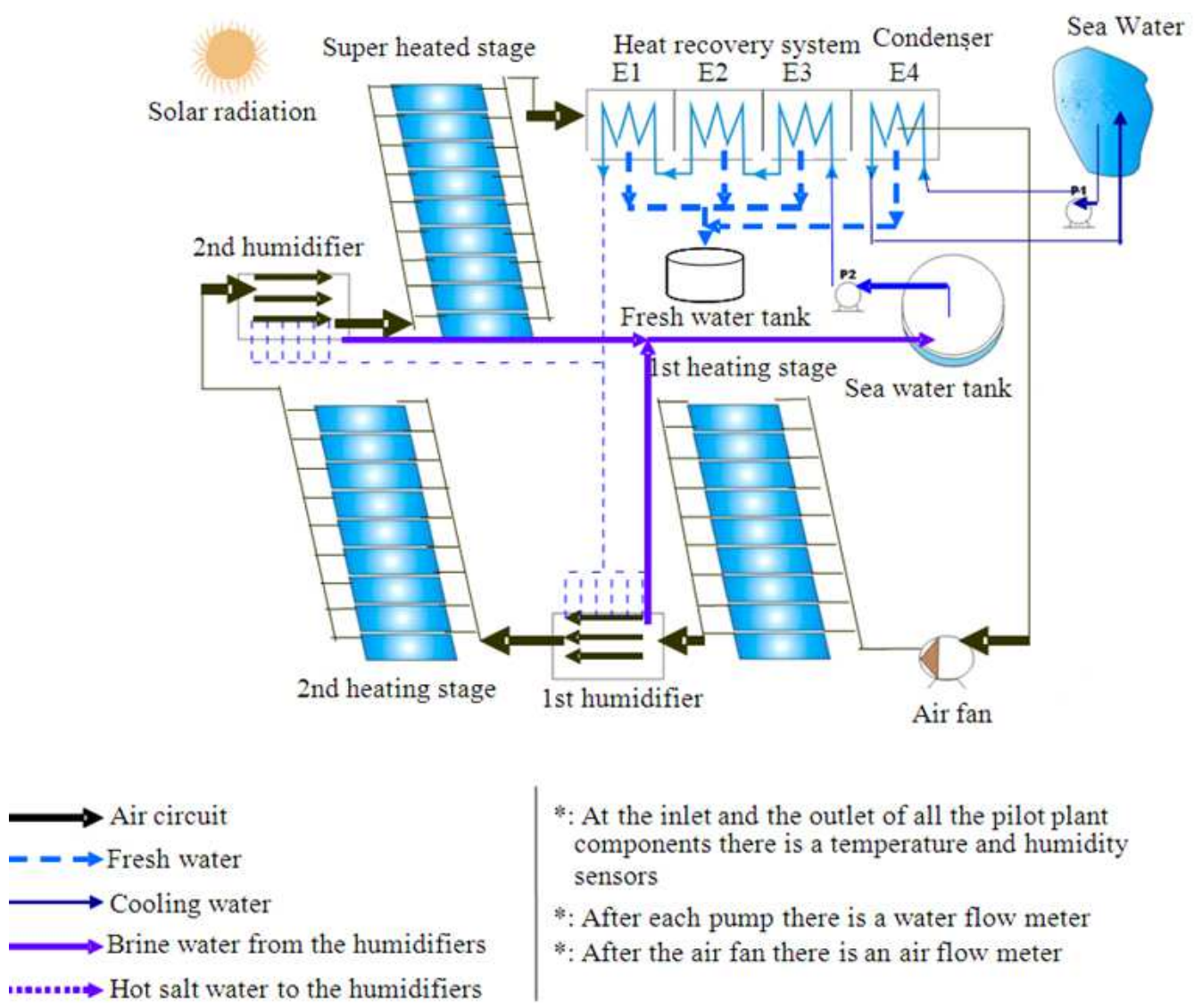

$$
\begin{aligned}
& \text { *: At the inlet and the outlet of all the pilot plant } \\
& \text { components there is a temperature and humidity } \\
& \text { sensors } \\
& \text { *: After each pump there is a water flow meter } \\
& * \text { : After the air fan there is an air flow meter }
\end{aligned}
$$

Fig. 1. Flow sheet of the solar desalination pilot plant

Next, the seawater will be pumped further towards the humidifiers and return later to the water tank closing the loop. The condenser is fed by fresh seawater for cooling.

The main characteristics of this pilot plant are:

- It has two loops: Air and water loops

- Air entering into the humidifiers is heated up by hot air heated in solar collectors

- Water entering into the humidifiers is heated up using the heat recovery system and

- The superheated stage has a triple role: it is used to increase the water temperature at the inlet of the humidifiers, it allows the condensation at ambient temperature and finally prevents condensation in the pipes

\subsection{Difficulties Encountered on the Multiple Stage Humidification Operation}

The main technical difficulties encountered while operating multiple-stage -humidification pilot plant were:
- The low air heat capacity, the lengthy air piping and the high pressure drop in the different pilot plant components provoked water condensation in the piping and even in the second stage air solar collectors when minor solar irradiation fluctuation occurred

- Distilled water can be obtained only if the air is loaded by a significant quantity of water vapour at the exit of the humidifier. We found experimentally that $45 \mathrm{~g} \mathrm{~kg}^{-1}$ is a minimum absolute humidity, under which no condensation occurs at ambient temperature

- Some problems of corrosion began to appear in the pumps and in the heat exchangers, due to hardness of the saline seawater

Water temperature at the entry of the humidifier has great effect on the whole pilot plant productivity and hence the productivity is closely linked to the performance of the heat exchangers (heat recovery system). 


\subsection{Experimental Conditions}

The experiments presented in this study are conducted to investigate the importance of the heat recovery in the described desalination pilot plant. The results will be presented for the experimental conditions shown in the Table 1.

Where:

$\mathrm{M}_{\text {air }}$ : Air mass flow rate
$\mathrm{HR}_{\mathrm{a}}$ : Ambient relative humidity

$\mathrm{M}_{\mathrm{iwh}}$ : Water mass flow rate entering into the heat exchangers

$\mathrm{T}_{\mathrm{a}}$ : Ambient temperature

G : Solar irradiation intensity

$\mathrm{M}_{\mathrm{iwc}}$ : Seawater mass flow rate into the condenser (cooling water)

$\mathrm{T}_{\mathrm{iwc}}$ : Seawater temperature entering into the condenser

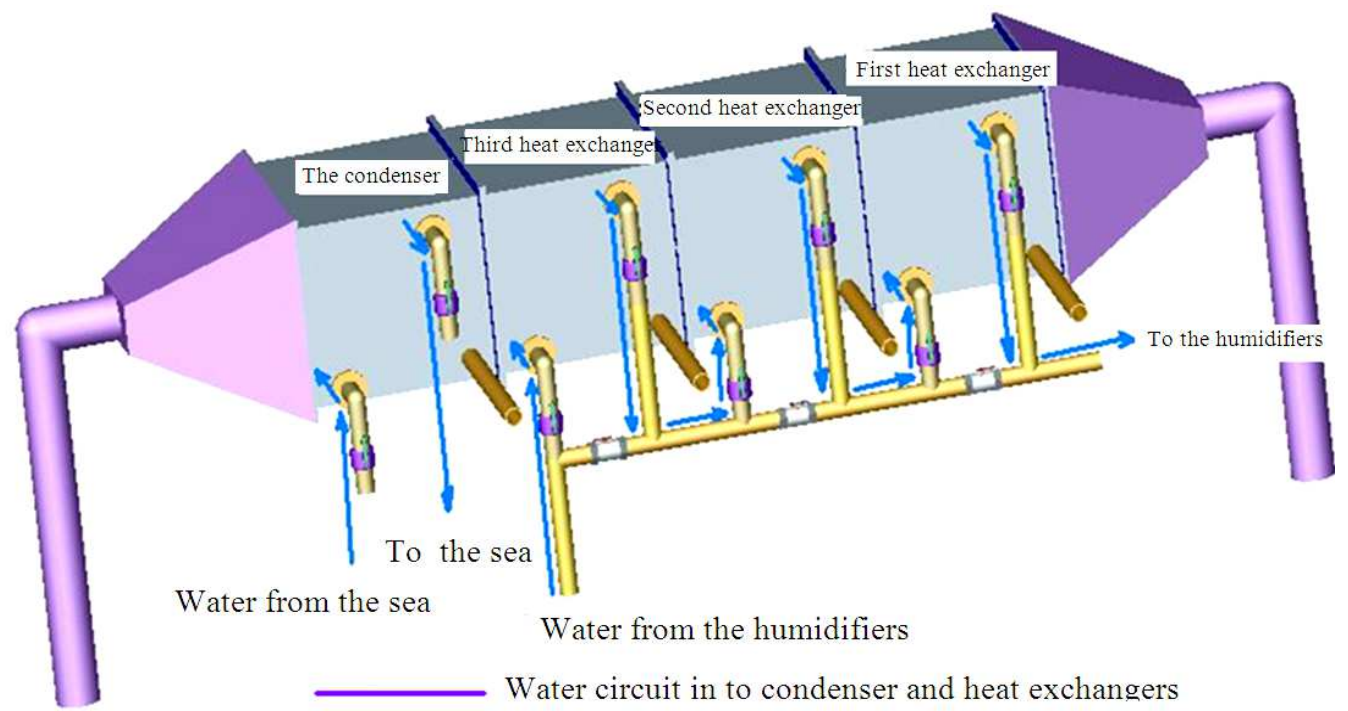

Fig. 2. Water circulation in the heat recovery system according to configuration 1: Three heat exchangers and the condenser

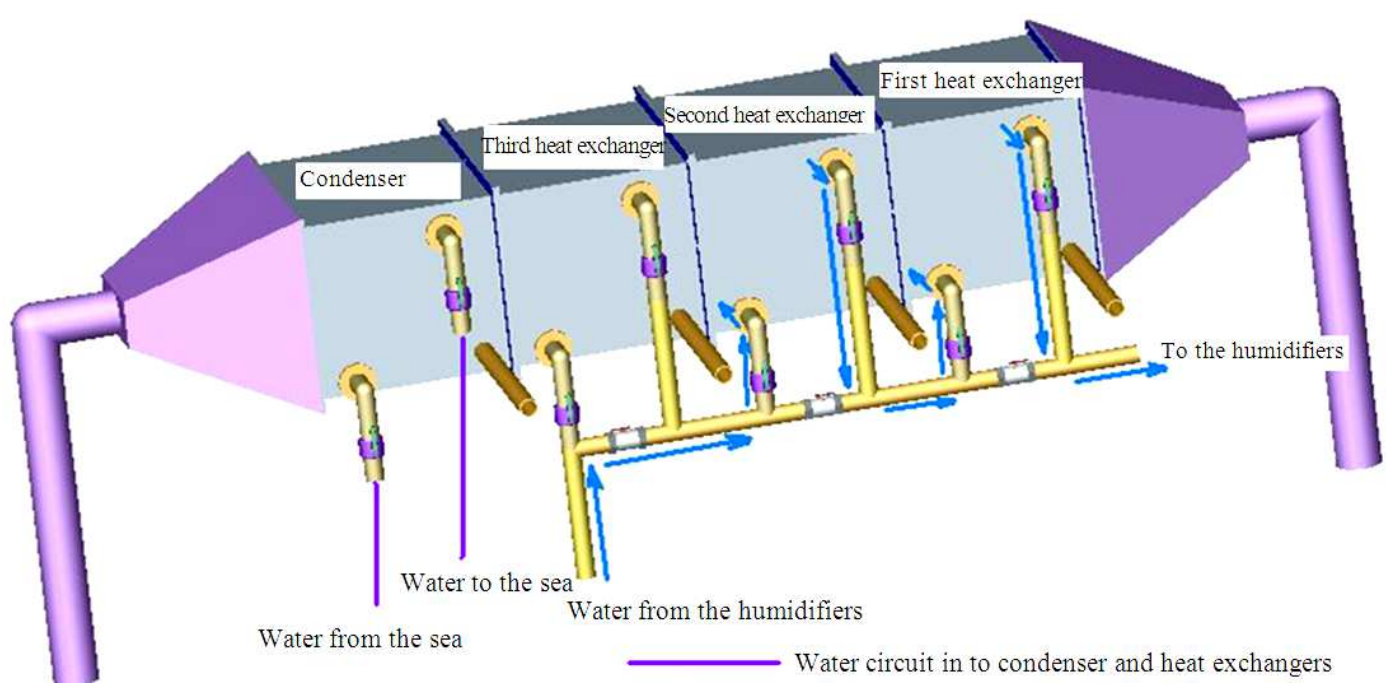

Fig. 3. Water circulation in the heat recovery system according to configuration 2: Two heat exchangers and the condenser 


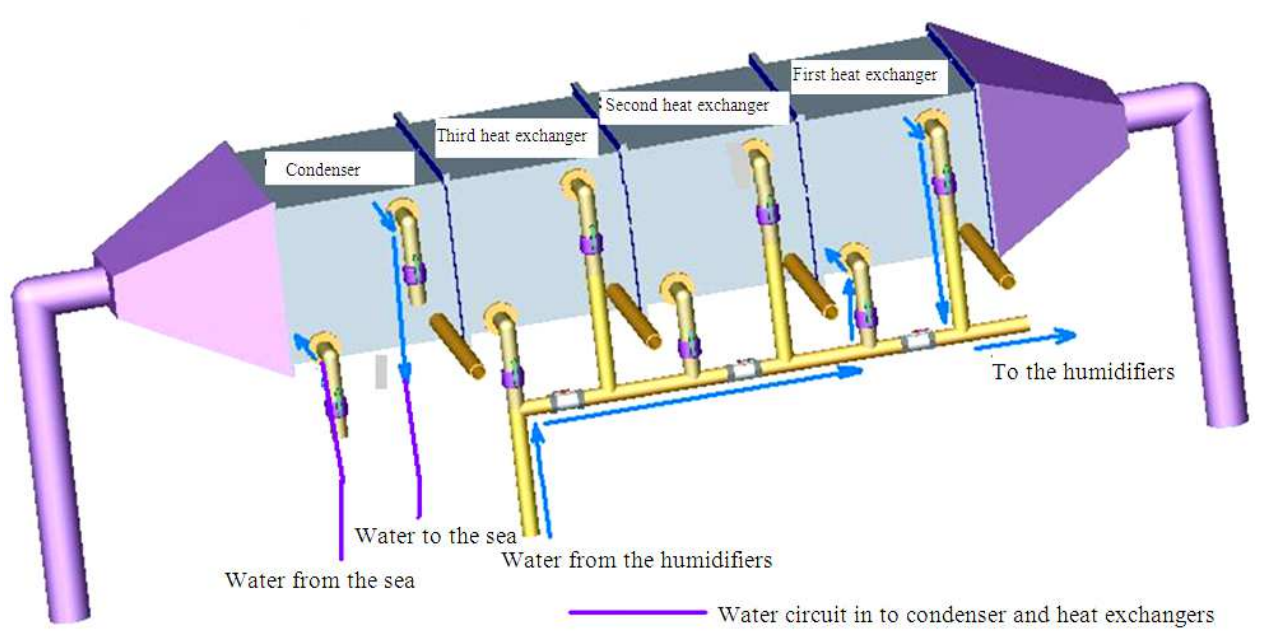

Fig. 4. Water circulation in the heat recovery system according to configuration 3: only one heat exchanger and the condenser

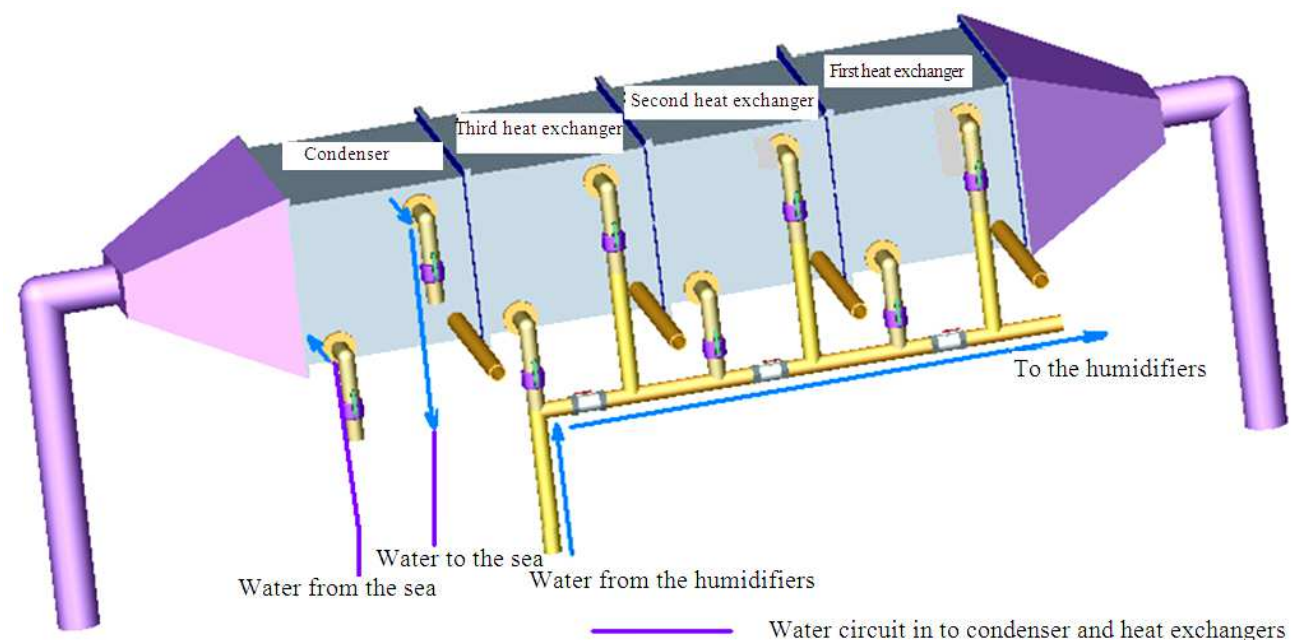

Fig. 5. Water circulation in the condenser according to configuration 4: without heat recovery system

Table 1. Experimental conditions

\begin{tabular}{ll}
\hline $\mathrm{M}_{\text {air }}$ & $2500 \mathrm{~kg} / \mathrm{h}$ \\
\hline $\mathrm{HR}_{\mathrm{a}}$ & $80 \sim 60 \%$ \\
$\mathrm{M}_{\text {iwh }}$ & $1000 \mathrm{~kg} / \mathrm{h}$ \\
$\mathrm{T}_{\mathrm{a}}$ & $24 \sim 27^{\circ} \mathrm{C}$ \\
$\mathrm{G}$ & $800 \sim 1000 \mathrm{~W} / \mathrm{m}^{2}$ \\
$\mathrm{M}_{\text {iwc }}$ & $3700 \mathrm{~kg} \mathrm{~h}^{-1}$ \\
$\mathrm{~T}_{\text {iwc }}$ & $20 \sim 22^{\circ} \mathrm{C}$ \\
\hline
\end{tabular}

In order to put stress on the role of the energy recovery system, four configurations of the pilot plant were investigated. These configurations are based on the number of heat exchangers in operation:
- First configuration: The pilot plant operates with three heat exchangers and a condenser as shown in Fig. 2

- Second configuration: The pilot plant operates with two heat exchangers and a condenser as shown in Fig. 3

- Third configuration: The pilot plant operates with only one heat exchanger and a condenser as shown in Fig. 4

- Fourth configuration: The pilot plant operates only with a condenser as shown in Fig. 5

The detailed characteristics of the heat exchangers are given in (Houcine et al., 2006). 


\section{RESULTS AND DISCUSSION}

The results are demonstrated in h-x diagrams (Fig. 69) in term of the humid air behaviour in the different components of the pilot plant: solar collectors, humidifier, heat exchangers and condenser. The humidifiers efficiency, inlet water temperature of the humidifiers and the daily water production for the different configurations are demonstrated as well in diagrammatically in Fig. 10-11.

\subsection{The Thermodynamic Behavior of Humid Air According to Heat Exchangers Number}

The h-x diagrams show that the difference between the humidifiers inlet and outlet absolute humidity decreases by the decrease of the number of the operating heat exchanger. In other words, the water quantity absorbed in the humidifier is directly linked to the number of the operating heat exchangers. This result can also be confirmed by studying the humidifier efficiency. Figure 10 presents the humidifiers efficiency and the humidifiers inlet water temperature for the different considered configurations. The efficiency of the humidifier is given by (Yanniotis and Xerodemas, 2003):

$$
\eta=\frac{\left(X_{o}-X_{i}\right)}{\left(X_{p}-X_{i}\right)}
$$

where, $X_{0}, X_{i}, X_{p}$ are respectively the outlet, inlet and interface absolute humidity ( $\mathrm{kg}$ water $/ \mathrm{kg}$ dry air).

Figure 10 shows that the humidifier efficiency increases with the increase in the number of the operating heat exchangers, which in turn causes a raise in the value of the humidifier inlet water temperature. This result, which agrees with literature results of Farid et al. (1998) and Ben-Amara et al. (2005), present the significant role of the heat exchangers. Moreover, the results show that the humidifier efficiency cannot normally exceed $45 \%$ when the system operates without heat exchangers.

The diagrams in Fig. 6-8 show that the air temperature in the heat exchangers decreases successively by $41.1^{\circ} \mathrm{C}$ in the first configuration, $39.2^{\circ} \mathrm{C}$ in the second configuration and $36^{\circ} \mathrm{C}$ in the third configuration. The heat quantity transferred from the air is transformed in form sensible heat to increase the water temperature at the exit of the heat exchangers (the water temperature at the outlet of heat exchangers are respectively $59.5^{\circ} \mathrm{C}$ in the first configuration, $57^{\circ} \mathrm{C}$ in the second configuration and $43^{\circ} \mathrm{C}$ in the third configuration) and then in form of latent heat to condense vapour (the absolute humidity decreases respectively by $17 \mathrm{~g} \mathrm{~kg}^{-1}$ in the first configuration, by $6 \mathrm{~g} \mathrm{~kg}^{-1}$ in the second configuration and by $0.1 \mathrm{~g} \mathrm{~kg}^{-1}$ in the third configuration).

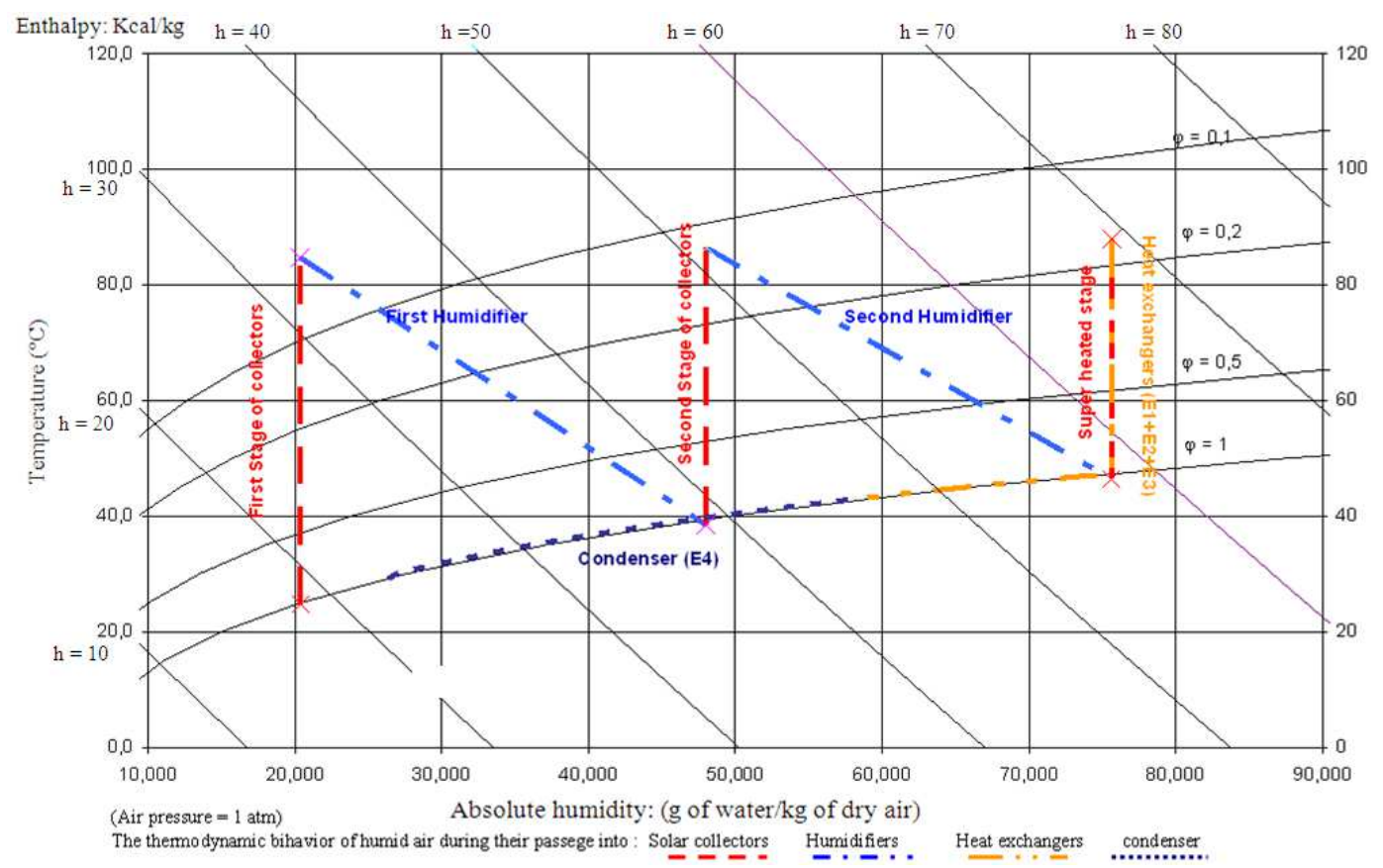

Fig. 6. Thermodynamic behaviour of humid air flowing in the two stages of heating-humidifying for the first configuration 


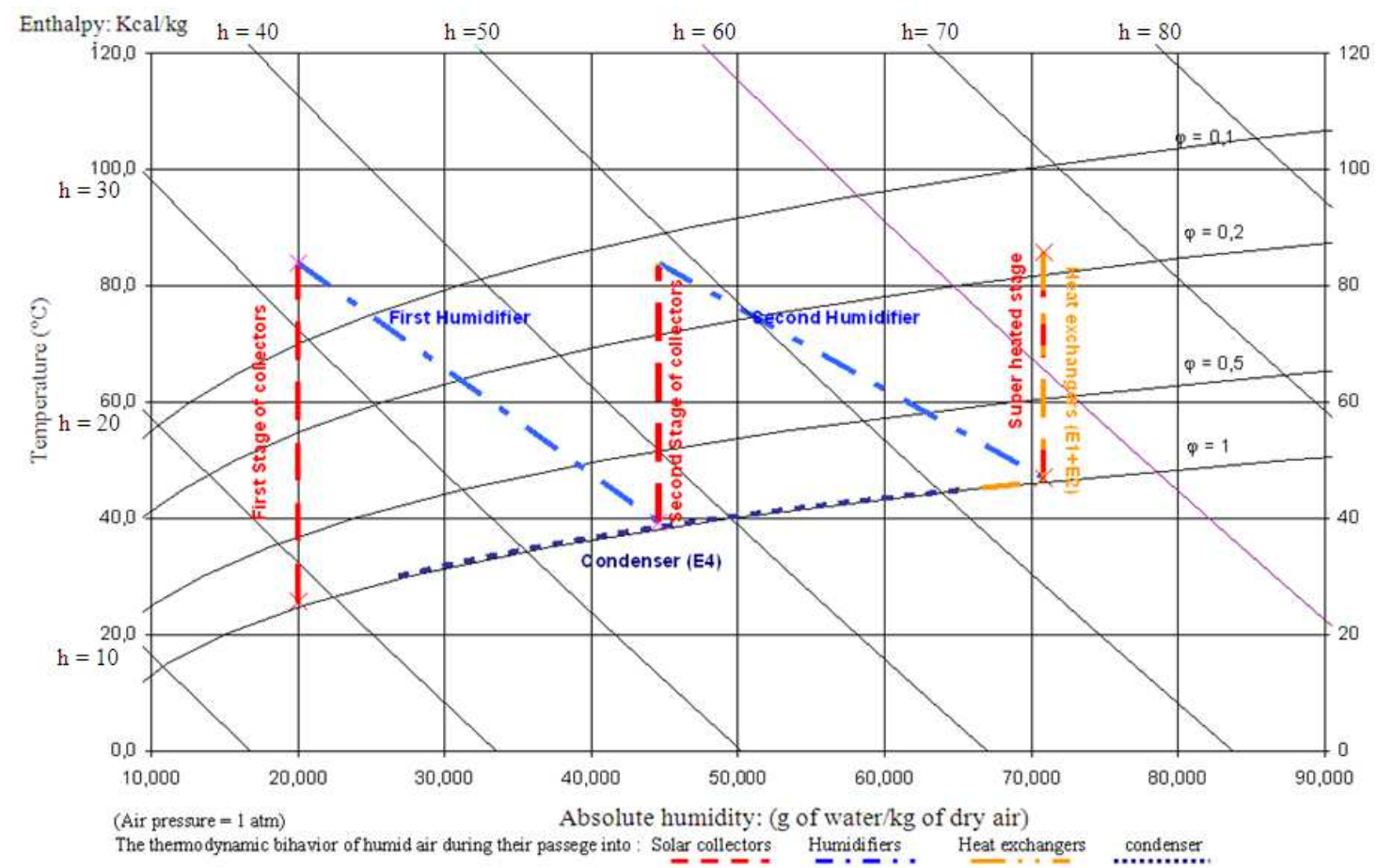

Fig. 7. Thermodynamic behavior of humid air flowing in the two stages of heating-humidifying for the second configuration

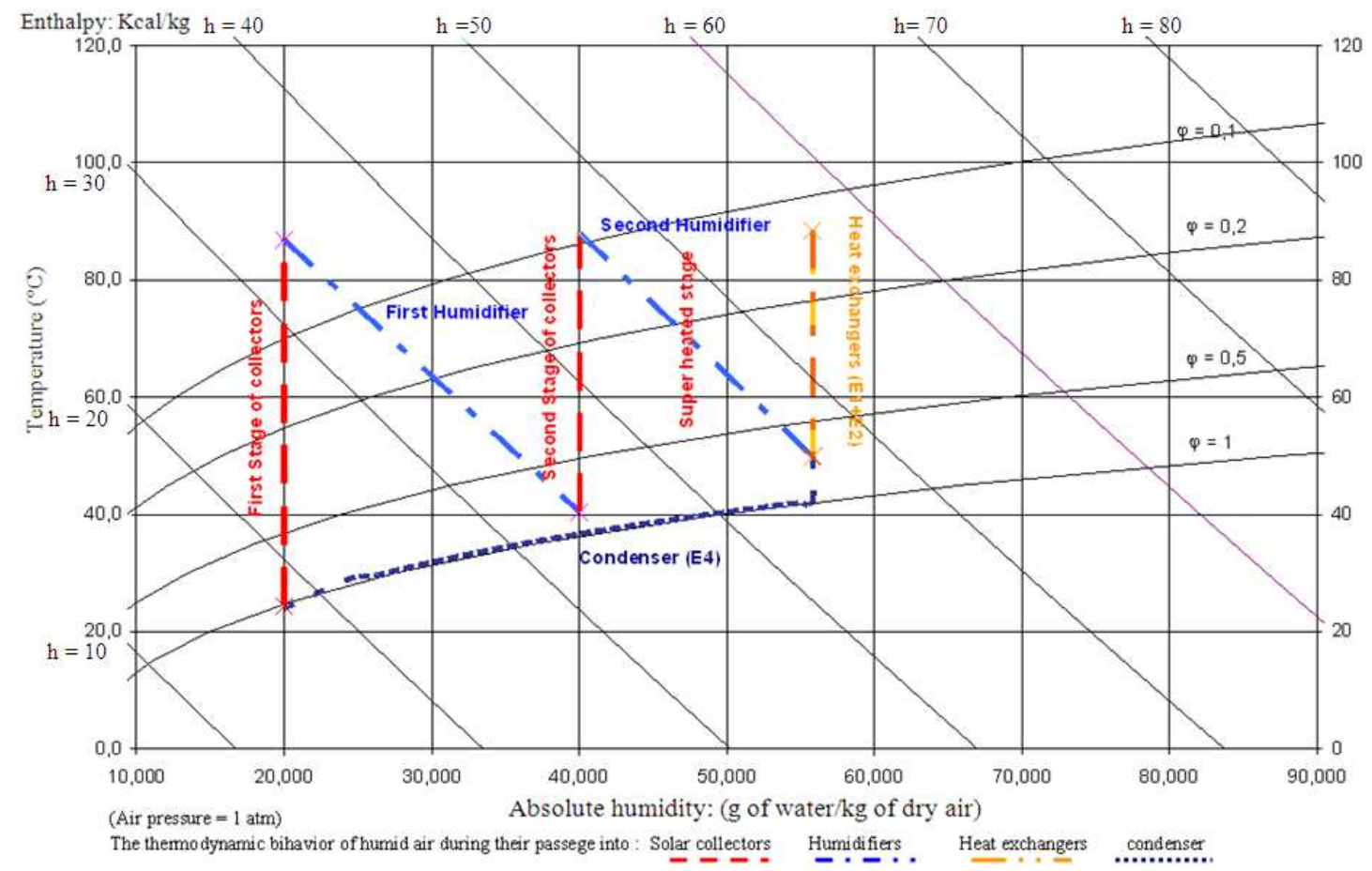

Fig. 8. Thermodynamic behavior of humid air flowing in the two stages of heating-humidifying for the third configuration 


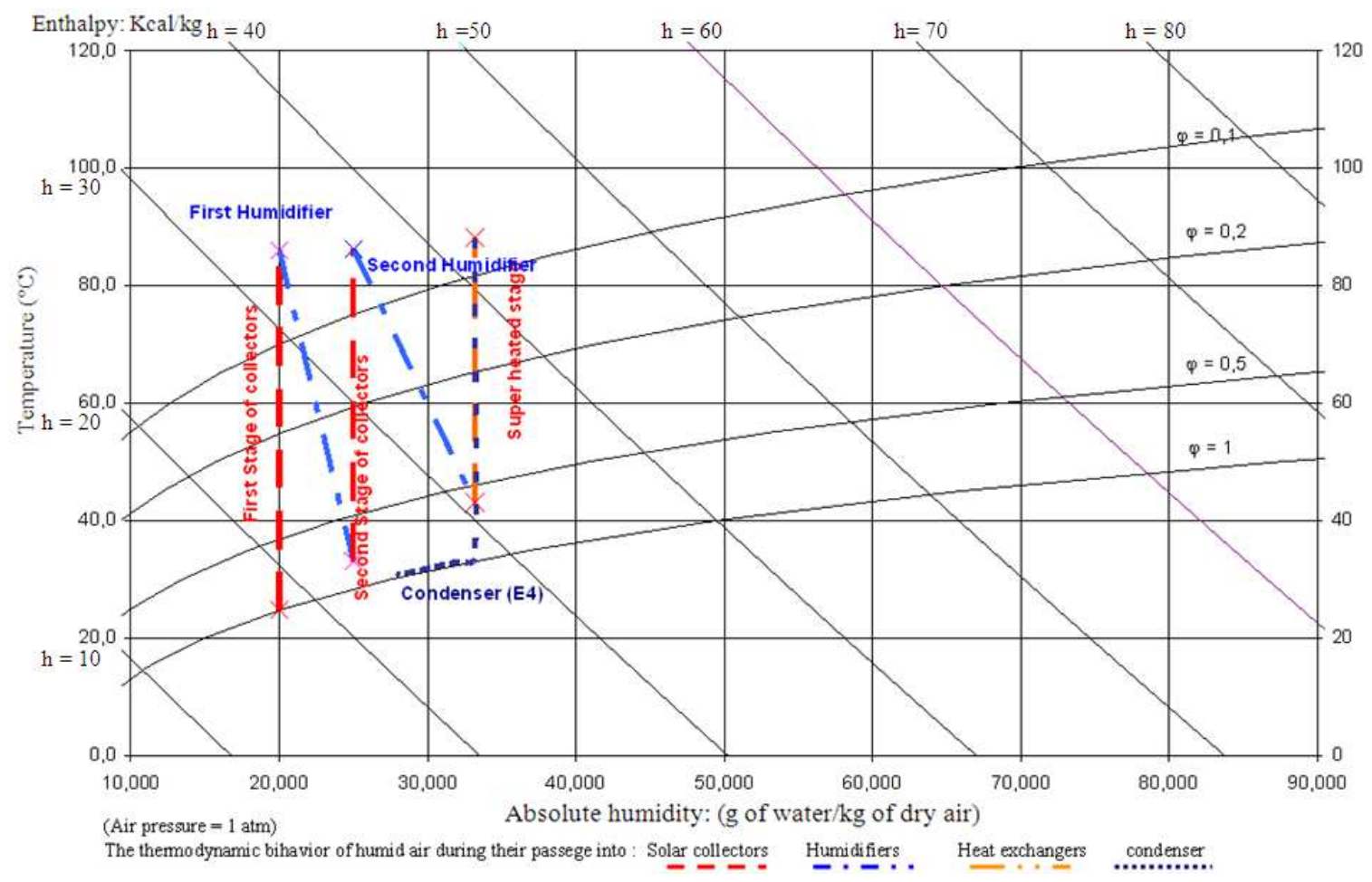

Fig. 9. Thermodynamic behavior of humid air flowing in the two stages of heating-humidifying for the forth configuration

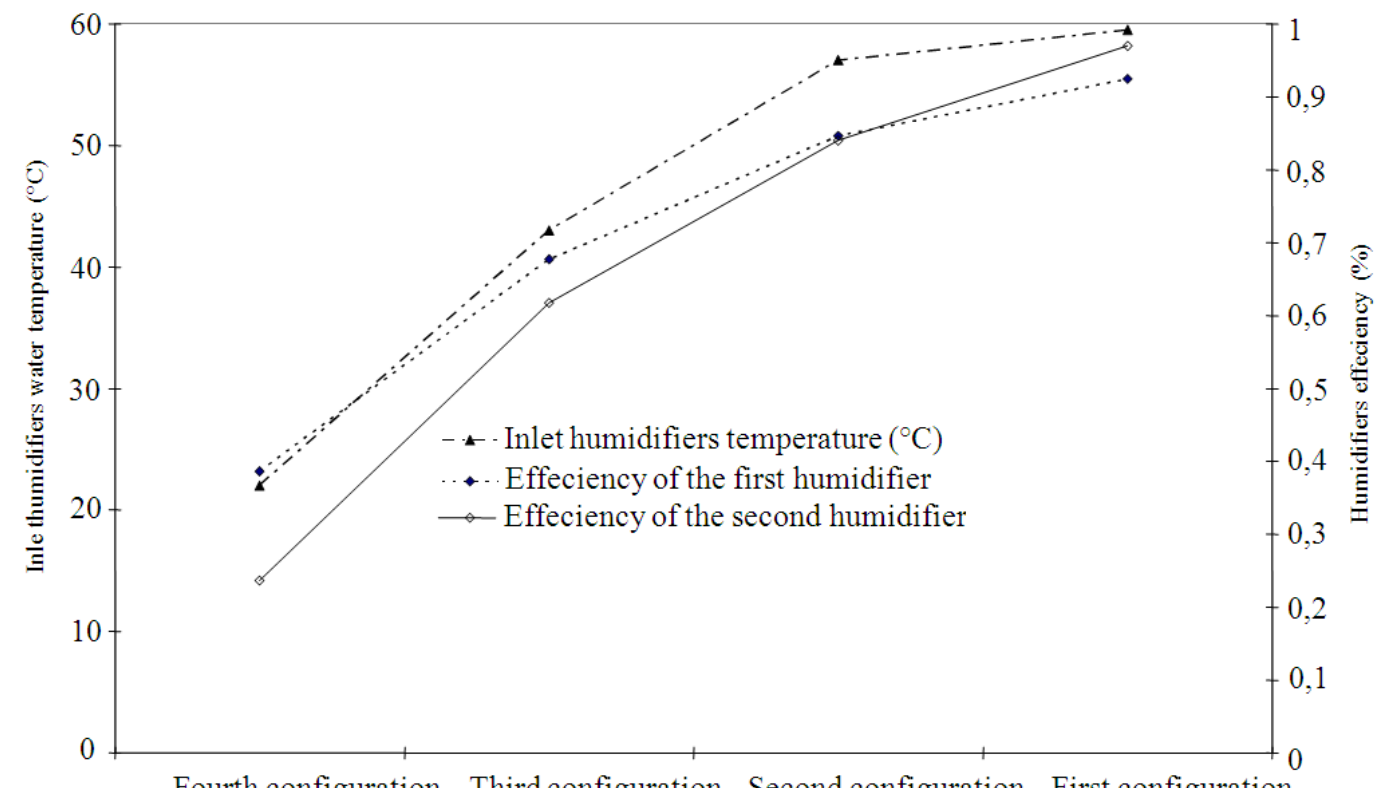

Fourth configuration Third configuration Second configuration First configuration

Diffrent studied configuration

Fig. 10. Humidifiers efficiency and inlet humidifiers water temperature for different configuration 


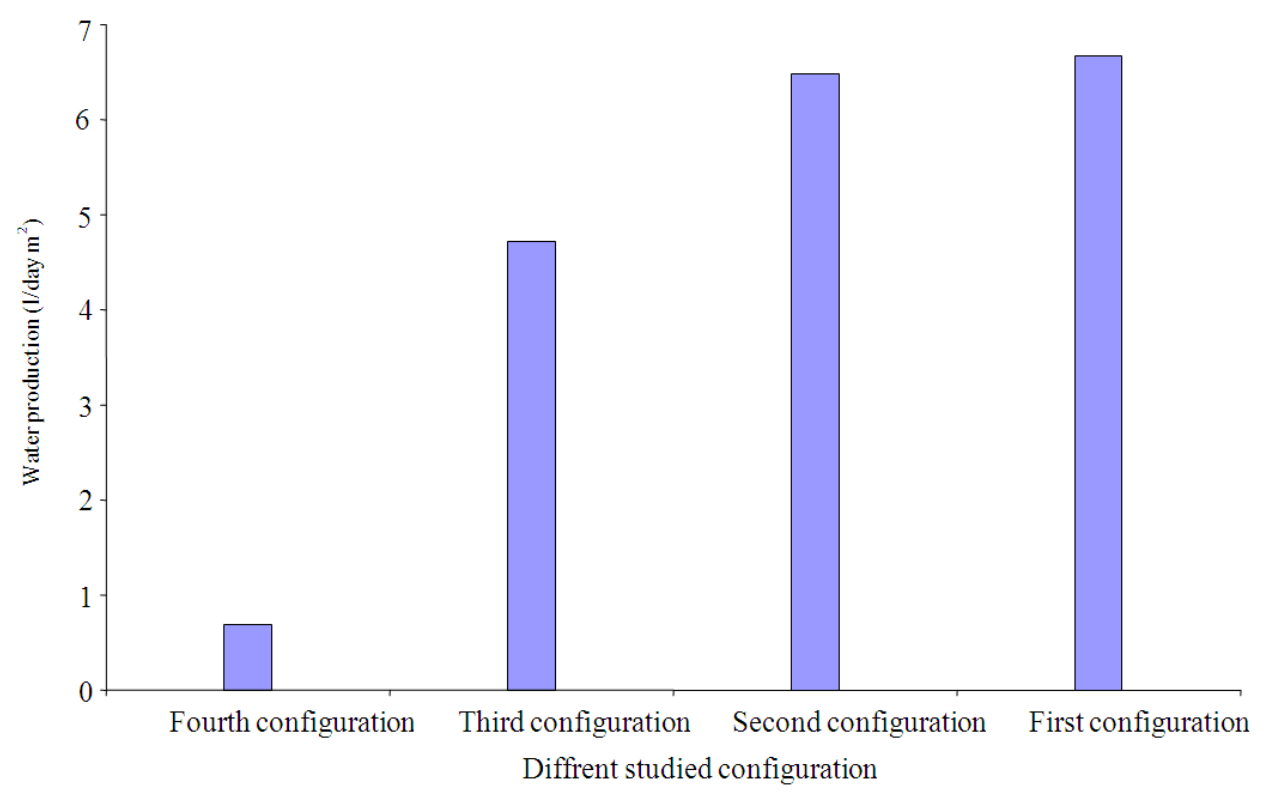

Fig. 11. Water production for different configuration

It can be deduced that for the third configuration, the heat extracted from the air is transformed totally in form of sensible heat and partially for the other configurations. The above listed results were used to choose the optimum number of the operating heat exchangers. It was found that two heat exchangers could be used efficiently as heat recovery system to satisfy heating up the water inside the heat exchangers up to a sufficient temperature to operate within the process.

\subsection{Water Production According to Heat Exchangers Number}

Figure 11 illustrates the daily water production per solar collector area of the pilot plant under the operating conditions of the selected four configurations. It can be seen that the size of the heat recovery system in such desalination pilot plant has a significant influence on the productivity of the plant. In deed, only an undersized quantity of fresh water is produced when operating the plant under the operating conditions of the fourth configuration (with only a condenser). Likewise, it can be noticed that the quantity of the produced water increases as the number of the heat exchangers of the heat recovery system increases. However, this goes up to a certain limit, to which an additional heat exchanger such as in configuration 1 does not improve the pilot plant production significantly.

\section{CONCLUSION}

To sum up, the experimental results obtained in this study were used to put stress on the importance of the heat recovery on the performance of the entire solar humidification-dehumidification desalination pilot plant. In short, results show that such a pilot plant working without the use of a heat recovery system (heat exchangers) is unable to deliver the desirable minimal amount distilled water at the exit of the condenser. Furthermore, the results have allowed to find out the optimum number of the heat exchangers that should be used to upgrade the overall efficiency of the desalination plant and therefore to deliver the largest possible amount of water production. The optimum number of heat exchangers to be used for heat recovery for the investigated setup was found to be two.

\section{REFERENCES}

Al-Enezi, G., H. Ettouney and N. Fawzi, 2006. Low temperature humidification dehumidification desalination process. Energy Conver. Manage., 47: 470-484. DOI: 10.1016/j.enconman.2005.04.010

Al-Hallaj, S., M.M. Farid and A.R. Tamimi, 1998. Solar desalination with a humidification-dehumidification cycle: Performance of the unit. Desalination, 120: 273-280. DOI: 10.1016/S0011-9164(98)00224-0 
Al-Hallaj, S., S. Parekh, M.M. Farid and J.R. Selman, 2006. Solar desalination with humidificationdehumidification cycle: Review of economics. Desalination, 195: 169-186. DOI: 10.1016/j.desal.2005.09.033

Ben-Amara, M., I. Houcine., A. Guizani and M. Maalej, 2004c. Theoretical and experimental study of a pad humidifier used in a seawater desalination process. Desalination, 168: 1-12. DOI: 10.1016/j.desal.2004.06.163

Ben-Amara, M., I. Houcine., A.A. Guizani and M. Maalej, 2004a. Experimental study of a multipleeffect humidification solar desalination technique. Desalination, 170: 209-221. DOI: 10.1016/j.desal.2003.11.009

Ben-Amara, M., I. Houcine., A.A. Guizani and M. Maalej, 2004b. Comparison of indoor and outdoor experiments on a newly designed air solar plate collector used with the operating conditions of a solar desalination process. Desalination, 168: 61-88. DOI: 10.1016/j.desal.2004.06.171

Ben-Amara, M., I. Houcine., A.A. Guizani and M. Maalej, 2005. Efficiency investigation of a newdesign air solar plate collector used in a humidification-dehumidification desalination process. Renew. Energy, 30: 1309-1327. DOI: 10.1016/j.renene.2004.09.019

Ben-Jemaa, F., I. Houcine and M.H. Chahbani, 1999. Potential of renewable energy development for water desalination in tunisia. Renew. Energy, 18: 331-347. DOI: 10.1016/S0960-1481(98)00807-6

Chafik, E., 2002. A new seawater desalination process using solar energy. Desalination, 153: 25-37. DOI: 10.1016/S0011-9164(02)01090-1

Chafik, E., 2003. A new type of seawater desalination plants using solar energy. Desalination, 156: 333348. DOI: 10.1016/S0011-9164(03)00364-3

Ettouney, H., 2005. Design and analysis of humidification dehumidification desalination process. Desalination, 183: 341-352. DOI: 10.1016/j.desal.2005.03.039

Farid, M. and A.W. Al-Hajaj, 1999. Solar desalination with a humidification-dehumidification cycle. Desalination, 106: 427-429. DOI: 10.1016/S00119164(96)00141-5
Farid, M.M., N.K. Nawayseh, A.A. Omar and A. Sabirin, 1998. Simulation of a solar desalination unit based on air humidification-dehumidification cycle. Int. J. Power Energy Syst., 18: 62-64.

Goosen, M.F.A., S.S. Sablani, W.H. Shayya, C. Paton and H. Al-Hinai, 2000. Thermodynamic and economic considerations in solar desalination. Desalination, 129: 63-89. DOI: 10.1016/S00119164(00)00052-7

Houcine, I., M. Ben-Amara., A. Guizani and M. Maalej, 2006. Pilot plant testing of a new solar desalination process by a multiple-effect-humidification technique. Desalination, 196: 105-124. DOI: 10.1016/j.desal.2005.11.022

Muller-Holst, H., M. Engelhardt and W. Scholkopf, 1999. Small-scale thermal seawater desalination simulation and optimization of system design. Desalination, 122: 255-262. DOI: 10.1016/S00119164(99)00046-6

Nawayseh, N.K., M.M. Farid, A.A. Omar, S.M. AlHallaj and A.R. Tamimi, 1997. A simulation study to improve the performance of a solar humidification-dehumidification desalination unit constructed in Jordan. Desalination, 109: 277-284. DOI : 10.1016/S0011-9164(97)00074-X

Nawayseh, N.K., M.M. Farid, S. Al-Hallaj and A.R. AlTimimi, 1999a. Solar desalination based on humidification process-I. Evaluating the heat and mass transfer coefficients. Energy Conver. Manage., 40: 1423-1439. DOI: 10.1016/S01968904(99)00018-7

Nawayseh, N.K., M.M. Farid, A.A. Omar and A. Sabirin, 1999b. Solar desalination based on humidification process-II Computer simulation. Energy Conver. Manage., 40: 1441-1461. DOI: 10.1016/S0196-8904(99)00017-5

Yanniotis, S. and K. Xerodemas, 2003. Air humidification for seawater desalination. Desalination, 158: 313-319. DOI: 10.1016/S00119164(03)00469-7 